\title{
COMPARATIVO DOS POTENCIAIS DE CORROSÃO DAS BARRAS DE AÇO INSERIDAS EM CORPOS DE PROVA MOLDADOS EM CONCRETO, EM ARGAMASSA ESTRUTURAL, EM ARGAMASSA POLIMÉRICA E EM GRAUTE CIMENTÍCIO, SOB ATAQUE INDUZIDOS DE CLORETOS
}

\author{
BEZERRA, JOSÉ EMIDIO ALEXANDRINO. \\ Profissão Prof. Me. Engo. Civil \\ Instituição: Universidade de Fortaleza \\ Estado; Pais: Ceará; Brasil \\ e-mail: joseemidiobezerra@outlook.com
}

\author{
OSHIRO, ANGEL. \\ Profissão: Prof. Ing. \\ Instituição: Universidad Tecnológica Nacional \\ Estado; País: Córdoba; Argentina \\ e-mail: oshiroangel@gmail.com
}

\author{
CABRAL, ANTÔNIO EDUARDO BEZERRA. \\ Profissão: Prof. Dr. Eng ${ }^{\circ}$ Civil \\ Instituição: Universidade Federal do Ceará \\ Estado; País: Ceará; Brasil \\ e-mail: eduardo.cabral@ufc.br
}

\author{
ARAUJO, RAUL DAVID. \\ Profissão: Graduando em Eng ${ }^{\mathrm{a}}$. Civil \\ Instituição: Universidade de Fortaleza \\ Estado; Brasil \\ e-mail: raul.david.araujo@hotmail.com
}

\section{RESUMO}

Este artigo apresenta a análise comparativa das linhas de tendência dos potenciais de corrosão em duas barras de aço inseridas em corpos de prova moldados em concreto, em argamassa estrutural, em argamassa polimérica e em graute cimentício, produtos utilizados em serviços de reparos estruturais. Foram submetidos a secagem em autoclave por cinco dias a $50{ }^{\circ} \mathrm{C}$ seguidos de umedecimento por imersão parcial em solução de 3,5\% de $\mathrm{NaCl}$ por dois dias para induzir a corrosão acelerada por cloretos. Para a medição da variação dos potenciais de corrosão foi utilizado um aparelho dotado de voltímetro e semicélula de cobre/sulfato de cobre. Após 12 ciclos foi verificado que o graute teve o melhor desempenho, seguido da argamassa polimérica, da argamassa estrutural e do concreto, nesta ordem. Palavras-chave:linha de tendência; potencial de corrosão; cloretos; graute; argamassa polimérica..

\begin{abstract}
This paper presents the comparative analysis of the corrosion potential trend lines in two steel bars inserted in specimens cast in concrete, structural mortar, polymeric mortar and cementitious grout, products used in structural repair services. They were autoclaved for five days at $50^{\circ} \mathrm{C}$ followed by moistening by partial immersion in $3.5 \% \mathrm{NaCl}$ solution for two days to induce chloride accelerated corrosion. For the measurement of the variation of the corrosion potentials, a device with voltmeter and copper / copper sulphate semi cells had used. After 12 cycles, it had verified that the grout had the best performance, followed by the polymeric mortar, the structural mortar and the concrete, in this order.
\end{abstract}

Keywords: tendency line; corrosion potential; chlorides; grout; polymeric mortar.

\section{INTRODUÇÃO}

A corrosão das armaduras do concreto é causada fundamentalmente pela carbonatação do concreto e interação com cloretos. A este respeito, HELENE (2014) afirma que a perda da proteção natural da armadura pelo cobrimento de concreto pode ocorrer por meio de diversos mecanismos sendo preponderantes a despassivação por carbonatação e por ação dos íons de cloro. Nas estruturas de concreto armado de edifícios e obras d'arte construídas nas áreas litorâneas que estão submetidas ao aporte de névoas salinas transportadas pelo vento os cloretos, com afirma Cascudo (1997) destroem a película passivante e juntamente com a água e oxigênio provocam a corrosão da armadura.

Os custos dos reparos são elevados e porisso, pesquisas sobre a eficiência dos inibidores de corrosão para o aço e nos materiais de reparos para o concreto são importantes para baixar os custou ou aumentar a durabilidade dos reparos.

Battagin (2010) citado por Borges (2015) afirmam que os agentes agressivos que atacam a pasta de cimento no concreto são os sais de magnésio e sulfatos, enquanto os cloretos são responsáveis pela corrosão das armaduras. Os cloretos, 
devido a suas dimensões muito pequenas tem grande mobilidade no interior do concreto podem chegar facilmente às armaduras.

GIUDICE (2016) afirma que a corrosão eletroquímica é na verdade uma rede de pilhas galvânicas em curto circuito dispostas sobre a superfície do metal e, como explicado por RÜSCH (1975) e citado por HELENE (1976), este mecanismo requer a existência de condutor, eletrólito, diferença de potencial elétrico e oxigênio para ocorrer e se manter.

No interior do concreto, inicialmente o aço está protegido pelo óxido formado na sua superfície pela combinação com álcalis do cimento, mas pode ser alterado pela carbonatação do concreto e por ataque de cloretos e sulfatos.

Segundo GIØRV (2014) "é bem conhecida a capacidade do concreto de proteger armaduras contra a corrosão, que se deve principalmente pela passivação eletroquímica das armaduras na solução alcalina presente nos poros do concreto, no entanto, a corrosão pode começar quando a passividade é rompida, parcial ou completamente, seja devido à carbonatação ou à presença de cloretos”.

Este processo de corrosão do aço no concreto tem uma fase inicial, na qual os agentes agressivos modificam as condições do concreto no entorno da barra, despassivando-a e com isto permite a formação de uma célula de corrosão, responsável pela propagação da corrosão. (PAZINI e MEIRA, 2013), sendo que os cloretos são os mais destruidores pela sua abundância nas áreas litorâneas onde localizam-se muitas estruturas de edifícios e por não se consumirem nas reações de oxi-redução.

Porisso, é relevante estudar a eficácia dos materiais usados em reparos estruturais e, para isto, pode-se utilizar ensaios não destrutivos, como a medida da resistividade do material, dos potenciais de corrosão e da difusão de cloretos.

A resistividade, pode ser usada para estimar a probabilidade de corrosão e segundo o CEB 192/88 para o cimento Portland a $20^{\circ} \mathrm{C}$ as condições da Tabela 1.

Tabela 1 Resistividade x Risco de corrosão Fonte: CEB 192/88

\begin{tabular}{c|l}
\hline Resistividadade $\mathrm{k} \Omega \mathrm{cm}$ & Probabilidade de corrosão \\
\hline$<100$ & Risco desprezível \\
\hline 50 a 100 & Risco baixo \\
\hline 10 a 50 & Risco moderado \\
\hline$<10$ & Risco alto \\
\hline
\end{tabular}

Da mesma forma, segundo Ribeiro e Cunha, (2018) a técnica da velocidade de pulso ultrasônico, permite obter informações sobre o módulo de elasticidade e a resistência à compressão, podendo identificar vazios no interior do material. A este respeito, POSETIERE e GIOIA (2017) eslarecem que o ultrassom é uma cria uma onda que supera os $20 \mathrm{KHz}$ e sería uma pertubação no meio em que se propaga, fazendo vibrar elasticamente as moléculas e átomos. Assim, a velocidade de pulso está relacionada com a qualidade do concreto e segundo a norma inglesa BS EM 12544/04, são admissíveis as seguintes condições (Tabela 2):

Tabela 2. Velocidade de pulso ultrassônico e qualidade do concreto. Fonte: BS EM 1254-4/04

\begin{tabular}{l|l}
\hline Velocidade de pulso ultrasônico $(\mathrm{m} / \mathrm{s})$ & Qualidade do concreto \\
\hline Maior do que $4.500 \mathrm{~m} / \mathrm{s}$ & Excelente \\
\hline Entre 4.500 e $3.500 \mathrm{~m} / \mathrm{s}$ & Bom \\
\hline Entre 3.500 e $3.000 \mathrm{~m} / \mathrm{s}$ & Duvidoso \\
\hline Entre 3.000 e $2.000 \mathrm{~m} / \mathrm{s}$ & Ruim \\
\hline Menor do que $2.000 \mathrm{~m} / \mathrm{s}$ & Muito ruim \\
\hline
\end{tabular}


O método de medição dos potenciais de corrosão mede a carga negativa provocada pelo movimento de elétrons liberados pelos íons ferrosos que se movem pelo eletrólito formado no concreto, fornecendo assim, informações sobre o estado de corrosão da armadura, de acordo com ZERBINO e CARRASCO (2012).

"É uma técnica bastante utilizada para medidas em laboratório e campo, devido à sua praticidade e por demandar por simples aparato para sua realização, além de ser uma técnica não destrutiva" (RIBEIRO e CUNHA, 2018).

A norma ASTM - C 876/91 estabelece os seguintes parâmetros para a possibilidade de corrosão em armaduras de concreto com base no potencial de corrosão medidos com semicélula de cobre/sulfato de cobre e que são apresentados na Tabela 3:

Tabela 3 Potencial x Probalidade de corrosão. Fonte: ASTM - C 876/91

\begin{tabular}{c|c}
\hline Potenciais de corrosão com semicélula de $\mathrm{Cu} / \mathrm{SO}_{4} \mathrm{Cu}$ & Probabilidade de corrosão \\
\hline Ecorr $<-200 \mathrm{mV}$ & Menos de $5 \%$ \\
\hline$-200 \mathrm{mV}<$ Ecorr $<-350 \mathrm{mV}$ & Cerca de $50 \%$ \\
\hline Ecorr $>-350$ & Mais de $95 \%$ \\
\hline
\end{tabular}

\section{OBJETIVO}

Este artigo tem como objetivo comparar a eficiência do concreto, da argamassa estrutural, da argamassa polimérica e do graute a base de cimento na proteção da armadura frente ao ataque de cloretos quando usados nos serviços de reparos estruturais.

\section{PROGRAMA EXPERIMENTAL}

O programa experimental foi planejado para obter-se medições dos potenciais de corrosão nos corpos de prova prismáticos de argamassa estrutural, argamassa polimérica, graute e de concreto com Fck $=24 \mathrm{MPa}(\mathrm{NBR} 9779 / 12)$ que servirá como base de referência. Foram submetidos à medições semanais para medir a evolução dos potenciais corrosão, após 12 ciclos de secagem ( 5 dias no forno `a $50^{\circ} \mathrm{C}$ ) e umedecimento em solução de $\mathrm{NaCL}$ a 3,5\% (2 dias).

\subsection{Caracterização dos materiais constituintes}

Os dados referentes aos materiais empregados para a elaboração do concreto usado nos corpos de provas são os seguintes:

Cimento Portland CP II F 32, composto com adição de fíler calcário entre $6 \%$ e $10 \%$. Blaine superior a $2.600 \mathrm{~cm} 2 / \mathrm{g}$, resistência à compressão > $32 \mathrm{MPa}$ aos 28 dias e atende à NBR 16697/18.

Areia grossa proveniente do Rio Chorozinho, na localidade de Criancó/Ce, com granulometria mostrada no Gráfico 1 e propriedades expostas na Tabela 4.

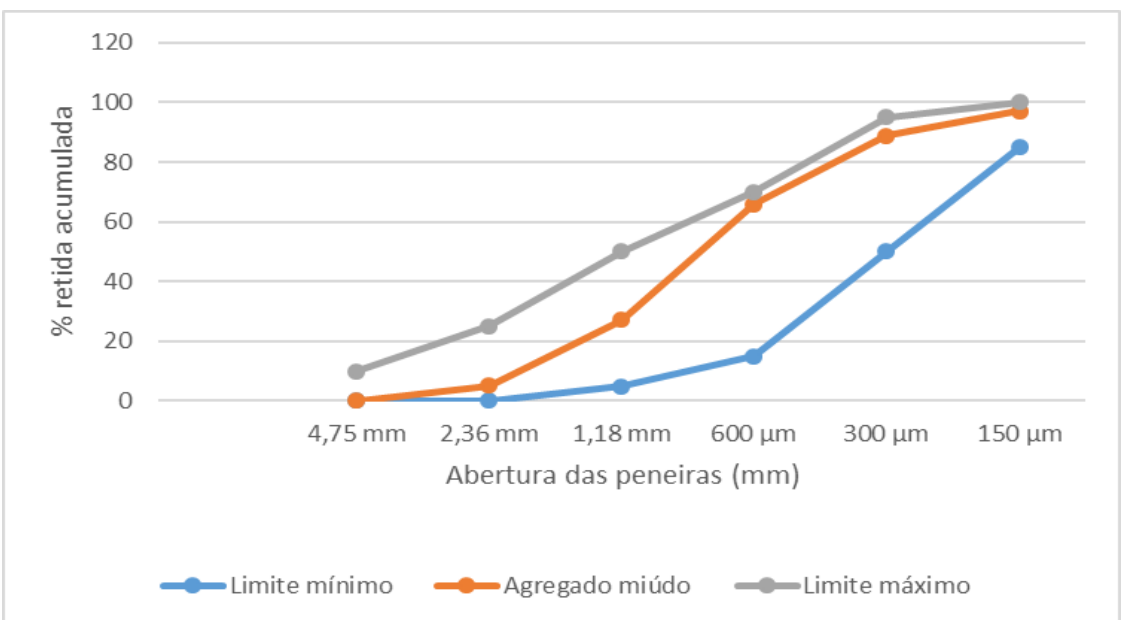

Gráfico 1 Análise granulométrica do agregado miúdo - NBR 7211/05. Autor (2019) 
Tabela 4. Propriedades físicas do agregado miúdo - NBR 7211/05. Fonte: O Autor (2019).

\begin{tabular}{l|c|c}
\hline Ensaio realizado & Resultado & Norma de ensaio \\
\hline Módulo de finura & 2,77 & NBR $7217 / 87$ \\
\hline D máx. característica & $2,36 \mathrm{~mm}$ & NBR $7217 / 87$ \\
\hline Massa específica & $2,62 \mathrm{~g} / \mathrm{cm}^{3}$ & NBR $9776 / 87$ \\
\hline Massa unitária & $1,48 \mathrm{~g} / \mathrm{cm}^{3}$ & NBR $7251 / 82$ \\
\hline Teor de materiais pulverulentos & $2,0 \%$ & NBR $7219 / 87$ \\
\hline
\end{tabular}

A brita tem diâmetro máximo nominal 9,5 mm e módulo de finura, 5,94, oriunda de Pacatuba, município da Região Metropolitana de Fortaleza tem granulometria de acordo com Gráfico 2.

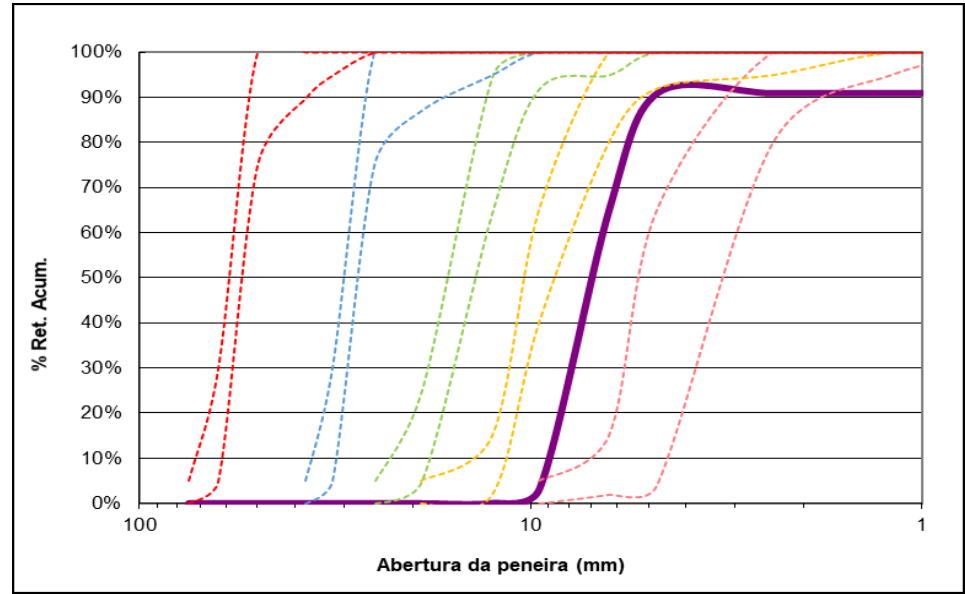

Gráfico 2 Análise granulométrica do agregado graúdo - ABNT NBR ISO 3310-1

- Concreto no traço 1:2:3 em peso com fator a/c de 0,6 e consumo de cimento de $344 \mathrm{~kg} / \mathrm{m}^{3}$, por ser o mais usado em estruturas com trinta anos de construção.

- Argamassa estrutural industrializada, composta de cimento Portland e aditivos, para reparos estruturais de 3 a 7 cm. (VEDACIT, $48^{\mathrm{a}}$. Ed.)

- Argamassa polimérica industrializada, cimentícia com agente adesivo acrílico, monocomponente de consistência tixotrópica.

- Graute industrializado, composto de cimento, agregados minerais e aditivo fluidificante, isento de cloretos e resistente à sulfatos.

- Aço CA 60 Os fios (CA60) são fabricados a partir do fio máquina (produto laminado a quente) com posterior processo de deformação a frio, como: trefilação ou laminação a frio. Trata-se de um aço com baixo teor de carbono que apresenta microestrutura composta de perlita e ferrita encruados pelo processo de deformação a frio. (ABNT, NBR 7480:2007)

Com estes materiais foram moldados corpos cilíndricos de concreto e de argamassa estrutural segundo a NBR 7215/96 para os ensaios de caracterização da absorção por imersão (NBR 9778/05), absorção por capilaridade (NBR 9779/12), difusão de cloretos (ASTM 1202/04 e ASTM C 1556/04), ensaios mecânicos como a resistência à compressão (NBR 9779/12). e módulo de elasticidade para a argamassa estrutural, argamassa polimérica e graute obtendo os seguintes resultados: (Tabela 5).

Tabela 5 Características dos materiais. Fonte: Autor (2019).

\begin{tabular}{l|r|r|r|r}
\hline \multicolumn{1}{c|}{ Ensaios / Material } & \multicolumn{1}{c|}{ Concreto } & Argamassa & Argamassa & \multicolumn{1}{c}{ Graute } \\
\cline { 2 - 5 } & \multicolumn{1}{c}{$1: 2: 3$} & Estrutural & Polimérica & Cimentício \\
\hline Absorção de água por capilaridade (g/cm2). S=19,64 & 0,47 & 0,38 & 0,26 & 0,31 \\
\hline Absorção de água por imersão. 72 hs. Ref (\%) & 7,96 & 12,64 & 6,68 & 8,13 \\
\hline Índice de vazios. 72 hs. Ref. (\%) & 20,8 & 23,89 & 6,28 & 17,54 \\
\hline Massa específica da amostra seca. 72 hs. Ref (\%) & 2,16 & 1,89 & 2,53 & 2,16 \\
\hline Massa específica da amostra saturada. 72 hs. Ref $(\%)$ & 2,34 & 2,14 & 2,69 & 2,33 \\
\hline
\end{tabular}




\subsection{Ensaio Acelerado de corrosão por indução de cloretos}

As barras de aço foram limpas com solução de ácido clorídrico 1:1 com 3,5\% de hexametilanotetramina, conforme a ASTM G - 1/03. Posteriormente, um terço das barras foram pintadas com produto a base de zinco e outro terço foram pintadas com o produto a base de nitrito no comprimento de $5 \mathrm{~cm}$, deixando $4 \mathrm{~cm}$ sem pintura. As demais foram deixadas sem pintura.

Os corpos de prova prismáticos têm as seguintes dimensões, mostrada na Figura 1.

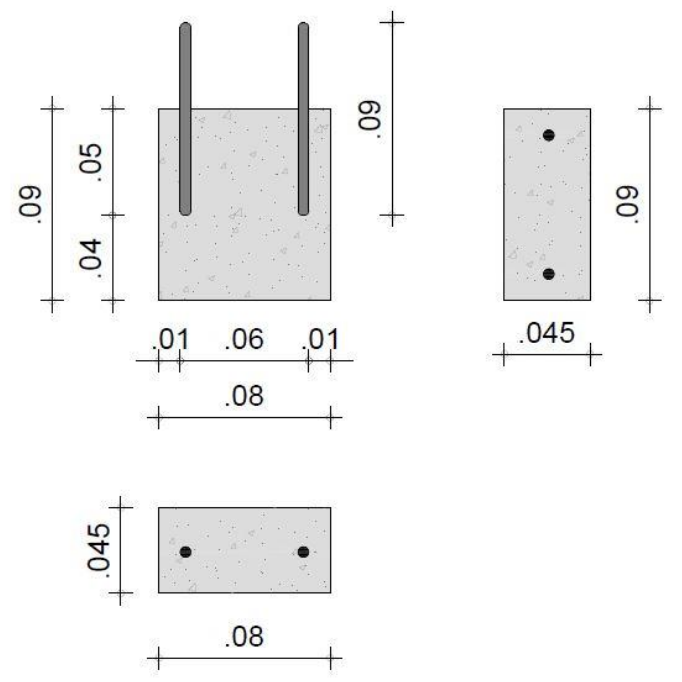

Figura 1 - Croquis do corpo de prova prismático. Fonte: Autor (2019).

Após o período de cura úmida de cinco dias e 16 dias de cura ao ar, os corpos de provas foram pintados na base, no topo e nas laterais maiores, deixando as laterais menores $(45 \times 80 \mathrm{~mm})$ desprotegidas para ataque pela solução de $\mathrm{NaCL}$ a $3,5 \%$.

O ensaio teve início no $24^{\circ}$ dia da moldagem colocando-os por cinco dias na estufa na temperatura de $50^{\circ} \mathrm{C}$ e feita a medição do potencial de corrosão. Em seguida, foram colocados numa bandeja contendo a solução até a metade da altura das barras de aço por dois dias e novamente medidos os potenciais de corrosão. Este procedimento foi repetido doze vezes.

Os ensaios foram realizados no Laboratório de Materiais de Construção da Universidade de Fortaleza, no primeiro semestre de 2019, de acordo com a sequência mostrada a seguir na Figura 2.

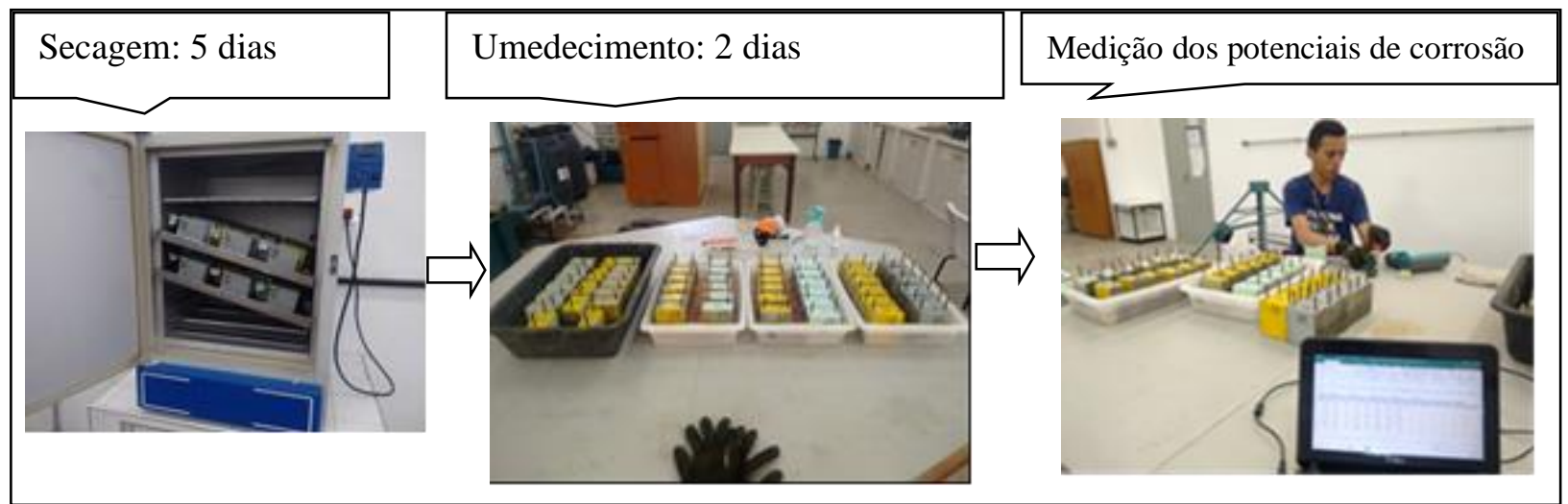

Figura 1: Sequência do Ensaio de Indução de corrosão por cloretos. Fonte: Autor (2019)

Desta forma se induz a corrosão da armadura por ação de cloretos de forma acelerada como constatado por vários pesquisadores, CABRAL (2000), CASCUDO, (1991); MONTEIRO, (1996); VASCONCELOS, (1997). 
Para a medição da velocidade de pulso foi usado um aparelho emissor/receptor de pulso ultrassônico seguindo o princípio do dispositivo de Werner.

As resistências características à compressão foram obtidas através de ensaios de rompimento na prensa do Laboratório de Materiais de Compressão da Universidade de Fortaleza.

\section{RESULTADOS}

4.1 Resultados dos ensaios para caracterização dos materiais:

A resistência a compressão Fck aos 28 dias, atingiu os seguintes valores de rompimento:

- Concreto $25 \mathrm{MPa}$

- Argamassa estrutural .......... $39 \mathrm{MPa}$

- Argamassa polimérica ----- $33 \mathrm{MPa}$

- Graute $40 \mathrm{MPa}$

A resistividade, medida em conformidade com a norma brasileira (NBR 9204:2012) mostrou os resultados aos 61 dias:

- Concreto $38,4 \mathrm{~K} \Omega . \mathrm{cm}$

- Argamassa estrutural $10,8 \mathrm{~K} \Omega . \mathrm{cm}$

- Argamassa polimérica $20,1 \mathrm{~K} \Omega . \mathrm{cm}$

- Graute $20,5 \mathrm{~K} \Omega . \mathrm{cm}$

Com estes valores de resistividade, de acordo com a Tabela 1 do CEB 192/88, todos os materiais têm um nível de resistividade adequado, pois o risco de corrosão é moderado.

O ensaio de ultrasom feito aos 90 dias nos corpos de prova cilíndricos 100x200 mm indica que a qualidade do material é boa, como se vê nos dados da Tabela 6 .

Tabela 6. Ensaio de Ultrassom. Fonte: Autor (2019).

\begin{tabular}{l|c|c|c|c|c|r}
\hline \multirow{2}{*}{ Material } & tempo pulso & $\mathrm{Vp}$ & $\mathrm{Vs}$ & $\mathrm{BS} \mathrm{EM}$ & $\mathrm{E}$ & \multicolumn{1}{c}{ Relação } \\
\cline { 2 - 7 } & $\mu \mathrm{s}$ & $\mathrm{m} / \mathrm{s}$ & $\mathrm{m} / \mathrm{s}$ & $1254-4 / 4$ & $\mathrm{GPa}$ & Agua/X \\
\hline Concreto 1:2:3 & 47,40 & 4225,00 & 2191,00 & Bom & 27,28 & 0,60 \\
\hline Argamassa estrutural & 50,00 & 3957,00 & 2341,00 & Bom & 25,50 & 0,21 \\
\hline Argamassa polimérica & 51,00 & 3927,00 & 2518,00 & Bom & 36,92 & 0,15 \\
\hline Graute & 53,30 & 3661,00 & 2616,00 & Bom & 28,93 & 0,17 \\
\hline
\end{tabular}

\subsection{Potenciais de corrosão}

Estabelecidos as características dos materiais utilizados, pode-se avaliar a eficiência dos revestimentos inibidores de corrosão e dos materiais quando submetidos ao ataque de cloretos. O método escolhido é indicado por oferecer resultados com boa precisão em períodos curtos. Assim, após doze ciclos foram obtidos os dados referentes a evolução dos potenciais de corrosão nos corpos de prova prismáticos de concreto, de argamassa estrutural, de argamassa polimérica e de graute, com barras de aço CA-60. As evoluções dos potenciais de corrosão são apresentadas (gráfico 3). 


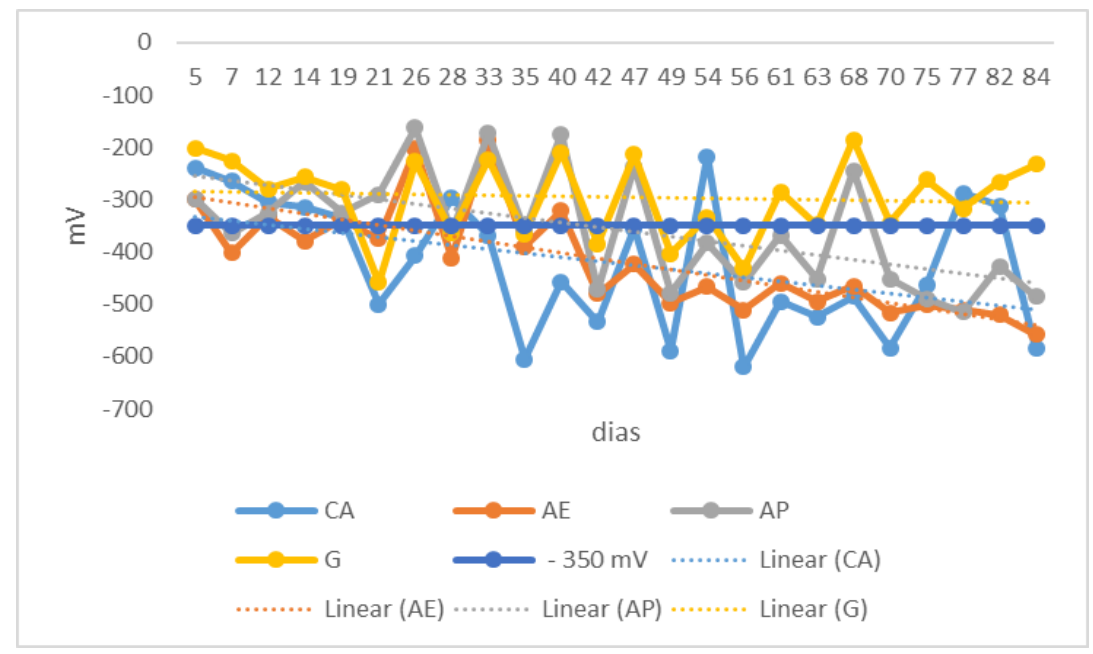

Gráfico 3. Potenciais de corrosão nas armaduras de concreto, argamassa estrutural e polimérica e graute.

Através das linhas de tendência dos potenciais de corrosão em cada material, verificou-se que para atingir o potencial de $-350 \mathrm{mV}$ (valor que indica a possibilidade de $95 \%$ de estar havendo corrosao no aço), os quatro materiais tiveram os seguintes resultados:

- Concreto ................................. 12 dias para atingir $-350 \mathrm{mV}$

- Argamassa estrutural ............. 21 dias para atingir $-350 \mathrm{mV}$

- Argamassa polimérica ........... 40 dias para atingir $-350 \mathrm{mV}$

- Graute .................................. até os 84 dias (12 ciclos) não atingiu $-350 \mathrm{mV}$

\section{CONCLUSÕES}

Os ensaios de caracterização dos materiais indicaram que todos os materiais são adequados para reparos estruturais em concreto armado, porém, o ensaio de indução de corrosão devido ao ataque de cloretos demonstrou a argamassa polimérica e o graute têm desempenho superior à argmassa estrutural e ao concreto no traço escolhido (ver Tabela 6). Isto, é razoável concluir, deve-se ao fato de que absorvem menos água e tem menos vazios e, portanto, são mais densos do que o concreto e a argamassa estrutural, (ver Tabela 5).

O graute teve o melhor desempenho, porque após 84 dias (12 ciclos) não atingiu o potencial de $-350 \mathrm{mV}$ (valor que indica 95\% de possibilidade para a armadura está se corroendo, segundo a ASTM - C 876/91). Nesta mesma pesquisa, a argamassa polimérica atingiu este valor com 40 dias, a argamassa estrutural com 21 dias e o concreto com 12 dias.

Deve-se salientar que, atualmente, por força da Norma NBR 6118:14, são usados concretos mais resistentes na construção das estruturas, porém, esta classe de resistência para o concreto - 20 a $25 \mathrm{MPa}$ foi bastante usada há cerca de trinta anos e são as que, atualmente, estão apresentando mais ocorrências de fissuração por corrosão da armadura.

\section{REFERÊNCIAS}

ASSOCIAÇÃO BRASILEIRA DE NORMAS TÉCNICAS NBR 6118:2014. Projeto de estruturas de concreto armado - Procedimento. Rio de Janeiro: ABNT, 2014.

ASSOCIAÇÃO BRASILEIRA DE NORMAS TÉCNICAS. NBR 9204: Concreto endurecido - Determinação da resistividade elétrica volumétrica - Método de ensaio, 2012. 12 p.

ASSOCIAÇÃO BRASILEIRA DE NORMAS TÉCNICAS NBR 8522:84. Módulo de elasticidade. Rio de Janeiro: ABNT, 1984.

ASSOCIAÇÃO BRASILEIRA DE NORMAS TÉCNICAS. NBR 5738: Concreto - Procedimento para moldagem e cura de corpos de prova. Rio de Janeiro, 2015. 9 p. 
ASSOCIAÇÃO BRASILEIRA DE NORMAS TÉCNICAS. NBR 5739: Concreto - Ensaio de compressão de corpos de prova cilíndricos. Rio de Janeiro, 2007. 9 p.

ASSOCIAÇÃO BRASILEIRA DE NORMAS TÉCNICAS. NBR 7211: 2005 Agregados para concreto - Especificação. Rio de Janeiro, 2005.

ASSOCIAÇÃO BRASILEIRA DE NORMAS TÉCNICAS. NBR 11578: 1991 Cimento Portland Composto. Rio de Janeiro, 1991.

ASSOCIAÇÃO BRASILEIRA DE NORMAS TÉCNICAS. NBR 8802: Concreto endurecido — Determinação da velocidade de propagação de onda ultrassônica. Rio de Janeiro, 2013. 8p.

ASSOCIAÇÃO BRASILEIRA DE NORMAS TÉCNICAS. NBR 95739:93. Migração por cloretos, ensaios mecânicos como a resistência à compressão. Rio de Janeiro, 1993.

ASSOCIAÇÃO BRASILEIRA DE NORMAS TÉCNICAS. NBR 9778: Argamassa e concreto endurecidos Determinação da absorção de água, índice de vazios e massa específica. Rio de Janeiro, 2005. 4 p.

ASSOCIAÇÃO BRASILEIRA DE NORMAS TÉCNICAS. NBR 7480. Aço destinado a armaduras para estruturas de concreto armado - Especificação. São Paulo: ABNT, 2018.

AMERICAN SOCIETY FOR TEST MATERIALS. ASTM - C 876: 1991. Standard Test Method for Corrosion Potentials of Uncoated Reinforcing Steel in Concrete corrosion potential.

AMERICAN SOCIETY FOR TEST MATERIALS. ASTM - G1: 2003. Preparing, cleaning and evaluating corrosion test especimens.

BASF. Manual Técnico, 2017. https://assets.master-builders-solutions.basf.com/pt-br. Acesso 29/05/2019.

BORGES, 1. F. Deterioração química e biológica do concreto. Dissertação de mestrado. Uberlância: UFU, 2015.

BRITISH STANDARDS EN 12504-4:2000. Testing Concrete. Determination of ultrasonic pulse velocity. London, 2000.

CASCUDO, Osvaldo. O controle da corrosão das armaduras de concreto. Inspeção e técnicas eletroquímicas. São Paulo: Pini,1997.

CIMENTO.ORG. CP II F - Cimento Portland composto com Fíler. Acesso 29/05/2019.https://cimento.org/cp-ii-f-32cimento-portland-composto-com-filer/

GIUDICE, CARLOS. Corrosión Metálica y mecanismo de protección de los pigmentos inhibidores em pinturas. Notas de clases. Fortaleza: UFC, 2016.

GJOV. ODD E. Durability and design of concrete structures in several enviroments. Oslo: CRC Press. 2 ed. 2014.

Helene, P.R.L. A NOVA NB 1/2003 (NBR 6118) E A VIDA ÚTIL DAS ESTRUTURAS DE CONCRETO. 2014. https://www.phd.eng.br/wp-content/uploads/2014/06/185.pdf

HELENE, P.R.L. Corrosão em armaduras para concreto armado. São Paulo: Pini, 1976.

PACHECO, j.; bilesky, P.; morais, T.R.; grando, f.; helene, P. considerações sobre o Módulo de Elasticidade do Concreto. 56 IBRACON. ISSN 2175-8182. Natal: Ibracon, 2014.

PAZINI. E.F.; MEIRA, G.R. Corrosión de armaduras en estructuras de hormigón. Boletín no 6. Mérida: Alconpat Internacional, 2013.

POSETIERE. M.J., GIOIA, C. Tecnología del Hormigón. Guia de Ensayos. Córdoba: Educo, 2017. 


\section{CBPAT 2020 \\ CONGRESSO BRASILEIRO DE PATOLOGIA DAS CONSTRUÇÕES \\ DE 15 A 17 DE ABRIL | FORTALEZA - CE \\ ISBN 978-65-86819-05-2}

PROCEQ S.A. Canin. Corrosion Analyzing Instrument. Operating instructions. Suitzerland. Schwerzenbach:2015.

PROCEQ S.A. Pundit PL 200. Shear Wave Transducers $250 \mathrm{kHz}$. Operating Instructions. Suitzerland. Schwerzenbach:.2015.

PROCEQ S.A. Resipod Operating Instrutions. Suitzerland. Schwerzenbach:.2015.

RIBEIRO, D. V. e CUNHA; M. P. T. Técnicas de avaliação e monitoramento da corrosão em estruturas de concreto armado. Corrosão e degradação em estruturas de concreto armado: teoria, controle e técnicas de análise e intervenção. Rio de Janeiro: Elsevier, 2018.

VEDACIT IMPERMEABILIZANTES. Manual Técnico, $48^{\mathrm{a}} \quad$ Edição. Acesso 29/05/2019.http://www.vedacit.com.br/uploads/biblioteca/manual-tecnico-vedacit-5.pdf.

ZERBINO, R. L.; CARRASCO, M.F. Hormigón endurecido. Ese material llamado hormigón. Buenos Aires: Asociación Argentina de Tecnología del Hormigón, 2012. 